\title{
Establishment of Evaluation Method for siRNA Delivery Using Stable Cell Line Carrying the Luciferase Reporter Gene
}

\author{
Ayako Iijma,${ }^{a}$ Rei Hachisu, ${ }^{b}$ Hideo Kobayashi $,{ }^{*}, a$ Kouichi Hashimoto, ${ }^{a}$ Daigo Asano, ${ }^{a}$ and \\ Hiroshi KIKUCHI $^{a}$ \\ ${ }^{a}$ Drug Metabolism \& Physicochemistry Research Laboratory, Tokyo R\&D Center, Daiichi Pharmaceutical Co., Ltd.; \\ 1-16-13 Kitakasai, Edogawa-ku, Tokyo 134-8630, Japan: and ${ }^{b}$ Hokkaido System Science Co., Ltd.; 2-1, Shinkawa Nishi \\ 2-1, Kita-ku, Sapporo, Hokkaido 001-0932, Japan. \\ Received January 25, 2007; accepted July 5, 2007; published online August 7, 2007
}

\begin{abstract}
We determined the influence of siRNA (short interfering RNA) for expression of plasmid DNA (pDNA), when mismatched siRNA and pDNA encoding $\beta$-galactosidase ( $\beta$-gal) were transfected into HeLa cells by the cotransfection method in which they were simultaneously added to the cells. Cationic liposomes (Lipofectamine2000) were used as a gene transfection reagent. The knockdown effect on $\beta$-gal was observed even when mismatched siRNA was used, and the effect depended on the amount of added mismatched siRNA. But, there was not a distinct difference of introduction of pDNA into cells between using mismatched siRNA and without using it. We considered that the cotransfection method should be avoided when we confirm RNAi efficiency. The reliable evaluation method for siRNA delivery in vitro was thus established by using NFAT reporter HeLa stable cell line or CHO (pMAM-luc) cell line that had DNA encoding luciferase. The following experimental conditions for each cell line were optimized: cell numbers seeded, total incubation times, concentrations of added inducers, and incubation times after addition of inducers. Transfection performance was compared for six commercially available reagents by this method. No commercially available transfection reagent, however, could reduce luciferase activity by less than one tenth without causing cellular cytotoxicity. Development of novel reagents providing higher transfection effects without cytotoxicity is needed.
\end{abstract}

Key words short interfering RNA; RNA interference; luciferase; transfection reagent; cotransfection

RNA interference (RNAi), ${ }^{1)}$ reported originally by Fire et $a l$. , is a powerful tool for silencing target genes in various organisms. ${ }^{2)}$ Recently, short interfering RNA (siRNA) is being regarded for application in pharmaceutical products. And, highly accurate in vitro methods are needed for the development of delivery technologies which can support siRNA therapy.

Generally, siRNA and plasmid DNA (pDNA) are introduced into cells by the cotransfection method to evaluate the RNAi effect of siRNA; but this method is considered to have serious complications because of some factors, such as, gene delivery method, transfection timing, and so on. To get a correct response, it is necessary to properly regulate the experimental conditions.

Several types of cotransfection methods have been used: the first is to transfect only siRNA into cells before pDNA; the second is to transfect only the plasmid into cells before siRNA, and the third is to transfect siRNA and the plasmid into cells at the same time.

We especially focused our attention on the last method, and determined the influence of mismatched siRNA for transfection of pCMV-SPORT- $\beta$-gal plasmid or Rhodaminelabeled pCMV-SPORT- $\beta$-gal plasmid. Lipofectamin $2000^{3)}$ was used as the transfection reagent. We also established an in vitro evaluation method for siRNA delivery using stable cell lines (NFAT reporter HeLa stable cell line or CHO (pMAM-luc) cell line) carrying the luciferase reporter gene. This experimental system is very simple as there is no need to transfect pDNA with this method. For that, we discussed here the few examination items needed to be established. We then checked the knockdown effect of the commercialized reagents by using this established method.

\section{MATERIALS AND METHODS}

Materials. Chemicals The pCMV-SPORT- $\beta$-gal plasmid (7854 bp) was obtained from Invitrogen (Carlsbad, CA, U.S.A.). And the pDNA was labeled with the Label IT CXRhodamine Labeling Kit (Mirus, Madison, WI, U.S.A.). Hoechst 33258 (DOJINDO, Tokyo, Japan) was used as the nuclear-fluorescence stain. Two kinds of siRNAs $(27$ mer) against the luciferase of NFAT reporter HeLa stable cell line (HeLa-luc cells) and CHO (pMAM-luc) cell line (CHO-luc cells) carrying the luciferase reporter gene were used in this study. The siRNA sequences for each luciferase gene were: HeLa-luc cells, 5'-ACAUCACGUACGCGGAAUACUUCGA-AG-3' (sense), 3'-UA-UGUAGUGCAUGCGCCUUAUGAAGCU-5' (antisense); CHO-luc cells, 5'-ACAUCACUUACGCUGAGUACUUCGA-AG-3' (sense), 3'-UA-UGUAGUGAAUGCGACUCAUGAAGCU-5' (antisense).

In addition, siRNA against the luciferase of HeLa-luc cells was used as mismatched siRNA for pCMV-SPORT- $\beta$-gal plasmid in the cotransfection study. They were obtained from iGENE (Tsukuba, Japan). Six commercially available transfection reagents were obtained from each manufacture: Lipofectamin2000 (Invitrogen), HiPerFect (Qiagen, Hilden, Germany), GeneSilencer (Genlantis, San Diego, CA, U.S.A.), Oligofectamin (Invitrogen), TransIT-TKO (Mirus, Madison, WI, U.S.A.), RNAiFect (Qiagen).

Phorbol 12-myristate 13-acetate (PMA; Sigma, St. Louis, MO, U.S.A.) and calcium ionophore A23187 (A23187; Calbiochem, San Diego, CA, U.S.A.) were used as inducers of HeLa-luc cells. Dexamethasone (Dex; Sigma) was used to induce CHO-luc cells.

Cell Culture The HeLa human cervical epithelial cell line (HeLa cells) was obtained from Dainippon Sumitomo 
Pharmaceutical Co., Ltd. (Osaka, Japan). The HeLa-luc cells were from Panomics (Fremont, CA, U.S.A.), and CHO-luc cells were from Health Research Resources Bank (Cell No. JCRB0136.1, Tokyo, Japan).

The HeLa cells were maintained in Minimum Essential Medium Eagle (MEM-E; Sigma) supplemented with 10\% fetal bovine serum (FBS). The HeLa-luc cells were maintained in Dulbecco's Modified Eagle's Medium (DMEM; Sigma) supplemented with $10 \% \mathrm{FBS}, 100$ units $/ \mathrm{ml}$ of penicillin (GIBCO, Carlsbad, CA, U.S.A.), $100 \mathrm{ng} / \mathrm{ml}$ of streptomycin (GIBCO) and $2 \mathrm{~mm}$ L-glutamine (GIBCO) and 100 $\mu \mathrm{g} / \mathrm{ml}$ of Hygromycin B (Invivogen, San Diego, CA, U.S.A.). The CHO-luc cells was maintained in Nutrient Mixture F-12 Ham (F-12 Ham; Sigma) supplemented with 10\% FBS and $400 \mu \mathrm{g} / \mathrm{ml}$ of G418 (Calbiochem).

Methods. [Exp. 1] Evaluation of Transfection Efficiency for the Cotransfection Method (Chart 1) The
HeLa cells were seeded at $2 \times 10^{4}$ cells/well in 24 -well plates with $10 \%$ FBS medium and incubated for $24 \mathrm{~h}$. One hundred microliters of serum-free medium containing $0,5,20$, and 80 pmol mismatched siRNA (siRNA for the luciferase of HeLa-luc cells) were mixed with $100 \mu \mathrm{l}$ of serum-free medium (MEM-E) containing $2 \mu \mathrm{l}$ of Lipofectamine2000 as the cationic liposomal gene transfection reagent. And then 0.4 or $0.8 \mu \mathrm{g}$ of the pCMV-SPORT- $\beta$-gal plasmid was added to the conjugate to form a complex with the reagent. After that the complex was incubated for $20 \mathrm{~min}$ at room temperature, and $300 \mu \mathrm{l}$ of medium containing 17\% FBS (final concentration, $10 \%$ FBS) was added. The HeLa cell culture medium was replaced by the medium containing the complex. After $24 \mathrm{~h}$ of incubation, the cells were fixed and stained with 5-bromo-4-chloro-3-indolyl- $\beta$-D-galactopyranoside (X-gal). After $8 \mathrm{~h}$ of incubation, the $\beta$-gal-positive, blue-stained cells were counted. ${ }^{4-6)}$

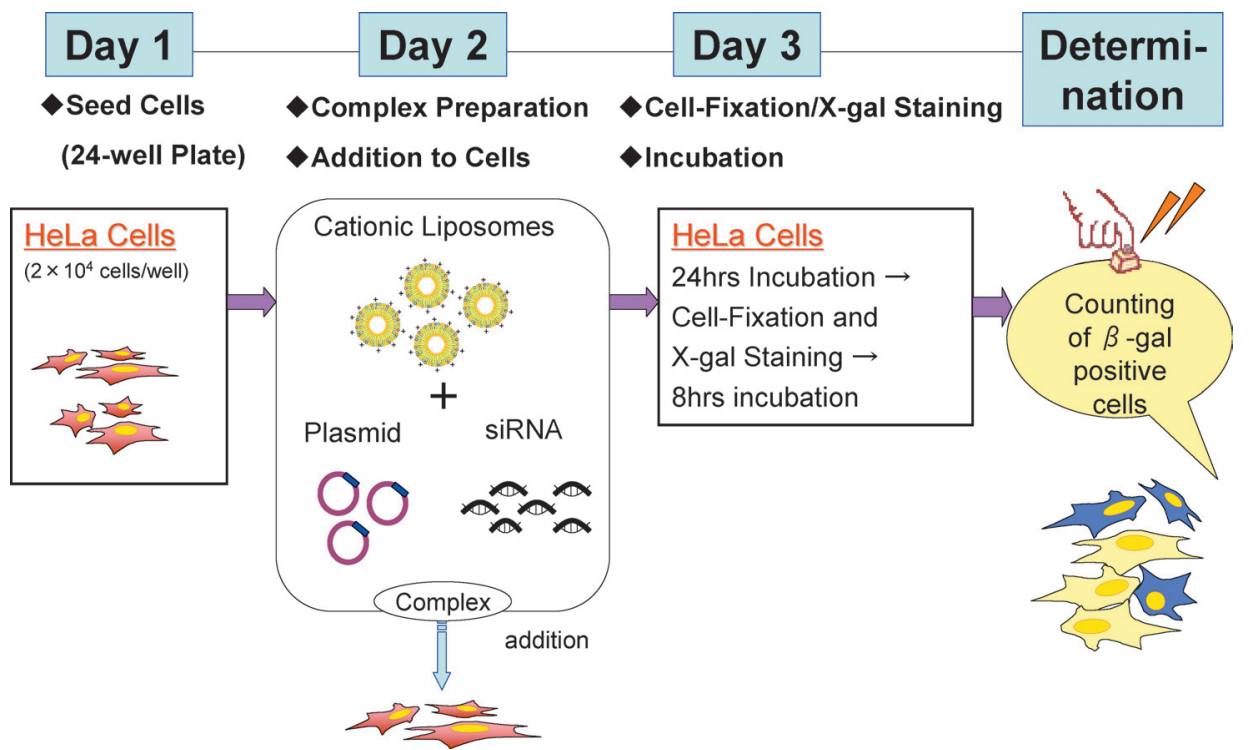

Chart 1. Cotransfection Method for Plasmid and siRNA in HeLa Cells

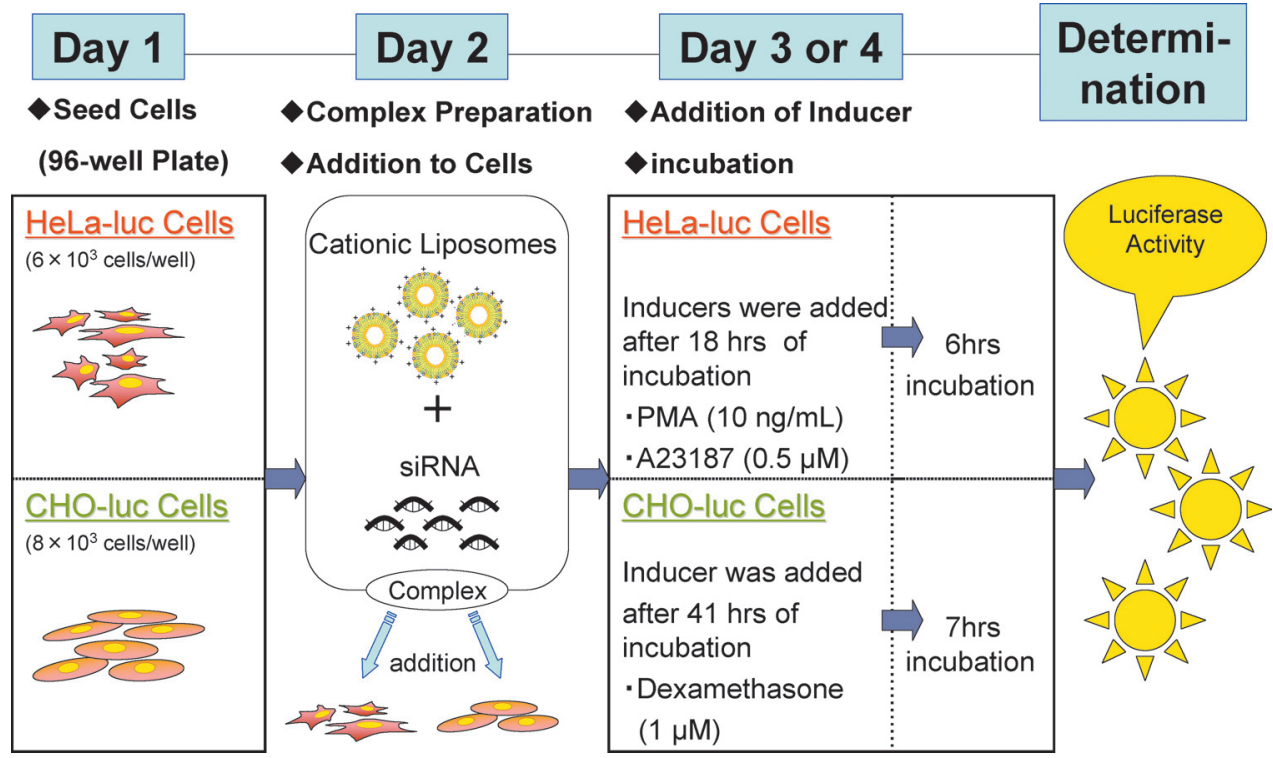

Chart 2. siRNA Transfection Method in HeLa-luc and CHO-luc Cells 
[Exp. 2] Observation of Rhodamine-Labeled pDNA Location by Using the Cotransfection Method and Confocal Laser Scanning Microscopy The HeLa cells were seeded at $1 \times 10^{5}$ cells in $3.5 \mathrm{~cm}$ glass-bottom dishes with $10 \% \mathrm{FBS}$ medium and incubated for $24 \mathrm{~h}$. Five hundred microliters of serum-free medium containing 0 or $400 \mathrm{pmol}$ mismatched siRNA (siRNA for the luciferase of HeLa-luc cells) were mixed with $490 \mu \mathrm{l}$ of serum-free medium (MEM-E) containing $10 \mu \mathrm{l}$ of Lipofectamine 2000 as the cationic liposomal gene transfection reagent. And then $2.0 \mu \mathrm{g}$ of pDNA (Rhodamine-labeled pCMV-SPORT- $\beta$-gal plasmid $)^{7)}$ was added to the conjugate to form a complex with the reagent. After that the complex was incubated for $20 \mathrm{~min}$ at room temperature, and $1.5 \mathrm{ml}$ of medium containing 17\% FBS (final concentration, 10\% FBS) was added. The HeLa cells culture medium was replaced by the medium containing the complex. The concentrations of siRNA and pDNA to be added were determined according to the condition of the $80 \mathrm{pmol}$ siRNA and $0.8 \mu \mathrm{g}$ of pDNA used for experiment 1 . After $24 \mathrm{~h}$ of incubation, nuclei were stained with Hochst 33258. The cells were then washed with $\mathrm{PBS}(+)$. Images were obtained through the bottom of the coverslip by confocal laser imaging with a TCS SP2 AOBS (Leica, Wetzlar, Germany). Exicitation for Rhodamine was $561 \mathrm{~nm}$. Exicitation for Hochst 33258 was $364 \mathrm{~nm}$. Analysis used Leica Confocal Software. ${ }^{7,8)}$

[Exp. 3] Establishment of an Evaluation Method for siRNA Delivery by Using HeLa-luc Cells or CHO-luc Cells Carrying the Luciferase Reporter Gene We optimized a few examination items for each cell line using the conditions stated below. Cells were seeded in 96-well black plates with $10 \%$ FBS medium. The HeLa-luc cells were seeded at $1.5,3,4.5,6 \times 10^{3}$ cells/well, whereas $\mathrm{CHO}-1$ uc cells were seeded at $4,6,8 \times 10^{3}$ cells/well, and both cell lines were incubated for $24 \mathrm{~h}$. After that, the $10 \%$ FBS medium was replaced by siRNA/transfection reagent complex and incubation was contained for a definite time. The cells were again incubated for a definite time after the reagent complex was replaced by $10 \%$ FBS medium containing a definite amount of inducers. The total incubation time for the examination after replacing the complex was $48 \mathrm{~h}$. PMA and A23187 were added as the inducer for HeLa-luc cells. Concentrations of PMA were $5,10,20$, and $50 \mathrm{ng} / \mathrm{ml}$. Concentrations of A23187 were $0.25,0.5,1$, and $2.5 \mu \mathrm{M}$. Similarly, Dex was added as the inducer for CHO-luc cells. Concentrations of Dex were 1, 5, 10, and $50 \mu \mathrm{M}$. Incubation times with the inducers of HeLa-luc cells were $6,7,8$, and $24 \mathrm{~h}$. And Incubation times with the inducer of $\mathrm{CHO}-\mathrm{luc}$ cells were $5,6,7$, and $8 \mathrm{~h}$.

On the one hand, we realized that HeLa-luc cells were more sensitive than CHO-luc cells to the cytotoxicity of Lipofectamine2000. With that, we optimized total incubation times for 24 and $48 \mathrm{~h}$ after the HeLa-luc cells medium was replaced by medium containing Lipofectamine 2000 and $10 \%$ FBS. And the cells were incubated for an additional $6 \mathrm{~h}$ after this medium was replaced by $10 \%$ FBS medium containing $10 \mathrm{ng} / \mathrm{ml}$ PMA or $0.5 \mu \mathrm{M} \mathrm{A} 23187$.

Amounts of Lipofectamine2000 added were 0.05, 0.1, 0.2, 0.4 , and $0.8 \mu \mathrm{l} /$ well.

After all of that, the cells were washed twice with $\operatorname{PBS}(-)$ and then lysed with $1 \times$ Passive Lysis Buffer (Promega, Madison, WI, U.S.A.). Luciferase activity was determined by a lu- minometer (Micro Lumat Plus LB96V, BERTHOLD, Bad Wildbad, Germany) with a luciferase assay kit (Promega). The amount of protein was determined by BCA protein assay (Pierce, Rockford, IL, U.S.A.).

Cellular cytotoxicity was observed by microscopy. And we judged cytotoxicity as 5 levels $(-, \pm,+,++,+++)$. "-" means Non-Cytotoxicity, " \pm " means Mild (cell destruction ratio was less than 15\%), "+" means Mild-Moderate (cell destruction ratio was $15-30 \%)$, " ++ " means Moderate (cell destruction ratio was 30-50\%), and " +++ " means Severe (cell destruction ratio was more than $50 \%$ ).

[Exp. 4] Evaluation of the Activity of Commercially Available Reagents for siRNA Transfection (Chart 2) We evaluated the activity of commercially available reagents for siRNA transfection by the method established in experiment 2. The method flow is shown in Chart 2. The amount of siRNA for luciferase was $4 \mathrm{pmol} /$ well. Amounts of added transfection reagents were determined following the package insert instructions. They were $0.2 \mu \mathrm{l} /$ well for Lipofectamine2000, $0.8 \mu \mathrm{l} /$ well for HiPerFect, $1.0 \mu \mathrm{l} /$ well for GeneSilencer, $0.6 \mu \mathrm{l} /$ well for Oligofectamine, $0.6 \mu \mathrm{l} /$ well for TransIT-TKO, and $1.6 \mu \mathrm{l} /$ well for RNAiFect. We used the following amounts of these reagents for HeLa-luc cells: $0.05,0.1$, and $0.2 \mu \mathrm{l} /$ well for Lipofectamine2000; $0.2,0.4$, and $0.8 \mu \mathrm{l} /$ well for HiPerFect; $0.25,0.5$, and 1.0 $\mu \mathrm{l} /$ well for GeneSilencer; $0.15,0.3$, and $0.6 \mu \mathrm{l} /$ well for Oligofectamine; $0.15,0.30$, and $0.6 \mu \mathrm{l} /$ well for TransITTKO; and $0.4,0.8$, and $1.6 \mu \mathrm{l} /$ well for RNAiFect. And we used the following amounts of these reagents for CHOluc cells: $0.03,0.2$, and $0.4 \mu \mathrm{l} /$ well for Lipofectamine2000; $0.13,0.8$, and $1.6 \mu \mathrm{l} /$ well for HiPerFect; 0.17, 1.0, and $2.0 \mu \mathrm{l} /$ well for GeneSilencer; $0.1,0.6$, and $1.2 \mu \mathrm{l} /$ well for Oligofectamine; $0.1,0.6$, and $1.2 \mu \mathrm{l} /$ well for TransIT-TKO; and $0.27,1.6$, and $3.2 \mu \mathrm{l} /$ well for RNAiFect.

\section{RESULTS AND DISCUSSION}

[Exp. 1] Evaluation of Transfection Efficiency for the Cotransfection Method (Chart 1) We did cotransfection by exposing HeLa cells to pCMV-SPORT- $\beta$-gal plasmid and mismatched siRNA. And we evaluated the influence of siRNA on pDNA transfection.

The amounts of plasmid used were 0.4 and $0.8 \mu \mathrm{g} /$ well,

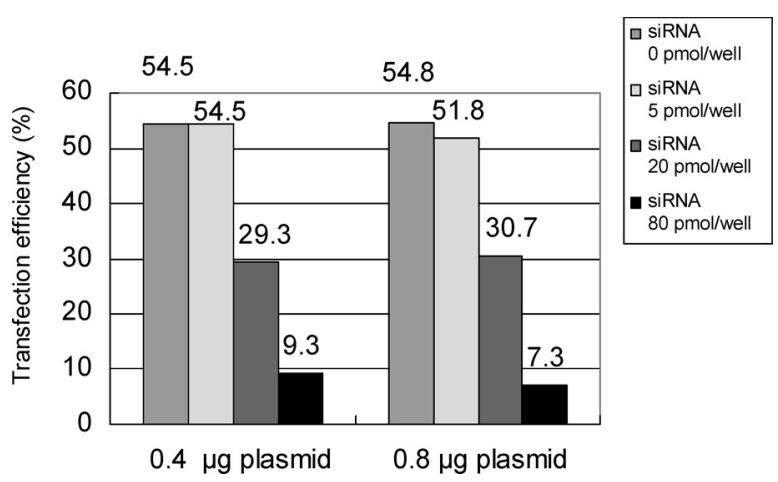

Fig. 1. Inhibition of pCMV-SPORT- $\beta$-gal Plasmid DNA Transfection by Mismatched siRNA in HeLa Cells Using Cotransfection Method

Transfection efficiency values (\%) were shown above the respective bars. Amounts of added plasmid DNA were 0.4 or $0.8 \mu \mathrm{g} /$ well (for 24 well). Amounts of added mismatched siRNA were $0,5,20$, and $80 \mathrm{pmol} /$ well. 

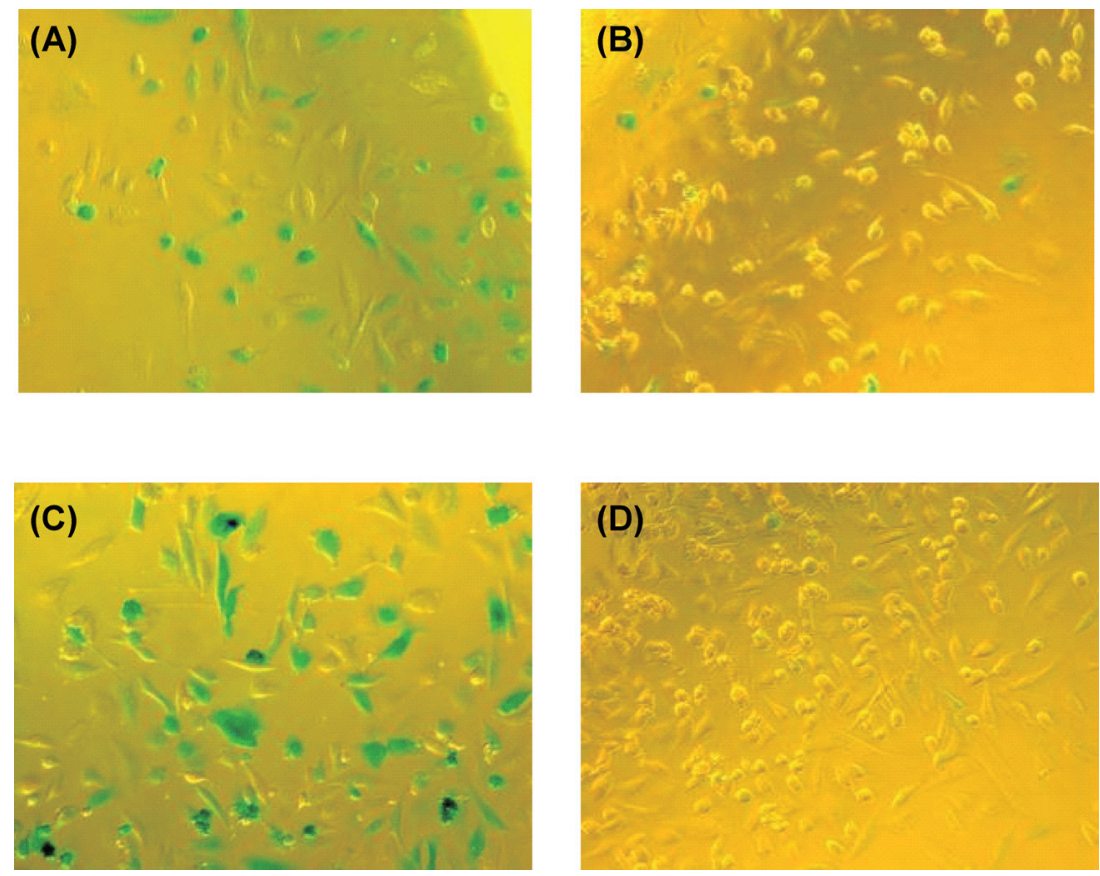

Fig. 2. Microscopic Images of the Cotransfection Results for pCMV-SPORT- $\beta$-gal Plasmid with Mismatched siRNA in HeLa Cells

HeLa cells were transfected with $0.4 \mu \mathrm{g} /$ well of pDNA without (A) and with 80 pmol/well of mismatched siRNA (B) (HeLa cells were seeded in 24 -well plates.). HeLa cells were transfected with $0.8 \mu \mathrm{g} /$ well of pDNA without (C) and with $80 \mathrm{pmol} /$ well of mismatched siRNA (D).

and the percentages of $\beta$-gal expression-positive cells were 54.5 and $54.8 \%$, respectively (Fig. 1). However, when 20 $\mathrm{pmol} /$ well of mismatched siRNA was added to HeLa cells in 24 well-plates, the percentage of $\beta$-gal expression-positive cells was about $30.0 \%$. In contrast, when $80 \mathrm{pmol} /$ well of mismatched siRNA was added to HeLa cells in 24 well plates, the percentage of $\beta$-gal expression-positive cells was less than $10 \%$ (Fig. 1). As just described, although increased amount of mismatched siRNA were used, the number of $\beta$ gal expression-positive cells was markedly decreased (Figs. 1, 2). Especially, Figs. 2C and D show a clear distinction between cells without and with the addition of $80 \mathrm{pmol} /$ well of mismatched siRNA. We also focused our attention on the anion equivalent ratio of siRNA for pDNA and calculated the ratio by using the following equations $(\mathrm{A})$ and $(\mathrm{B})$.

(A) siRNA anionic molar (pmol)

$$
=\mathrm{X}(\text { pmol }) \times 27 \text { (base) } \times 2 \text { (pair) }
$$

(B) pDNA anionic molar (pmol)

$$
=\mathrm{Y}(\text { pmol) } * \times 7854 \text { (base) } \times 2 \text { (pair) }
$$

*: $0.4 \mu \mathrm{g}$ pDNA $=0.077$ pmol, $0.8 \mu \mathrm{g}$ pDNA $=0.154 \mathrm{pmol}$

When the anion equivalent ratio of siRNA for pDNA was more than 0.45 , the transfection efficiency of the plasmid was decreased to a large degree (Table 1).

On the other hand, when we added mismatched siRNA to the HeLa-luc cells carrying the lucferase reporter gene, there was no difference in luciferase activity in the presence or absence of mismatched siRNA. The off-target effect of the mismatched siRNA was not observed in this case (data not shown).

[Exp. 2] Observation of Rhodamine-Labeled pDNA Location by Using the Cotransfection Method and Confocal Laser Scanning Microscopy To analyze the mechanism of the result for experiment 1 , we did cotransfection by using HeLa cells cultured without or with $400 \mathrm{pmol} / \mathrm{dish}$ of mismatched siRNA and $2.0 \mu \mathrm{g} /$ dish of Rhodamine-labeled
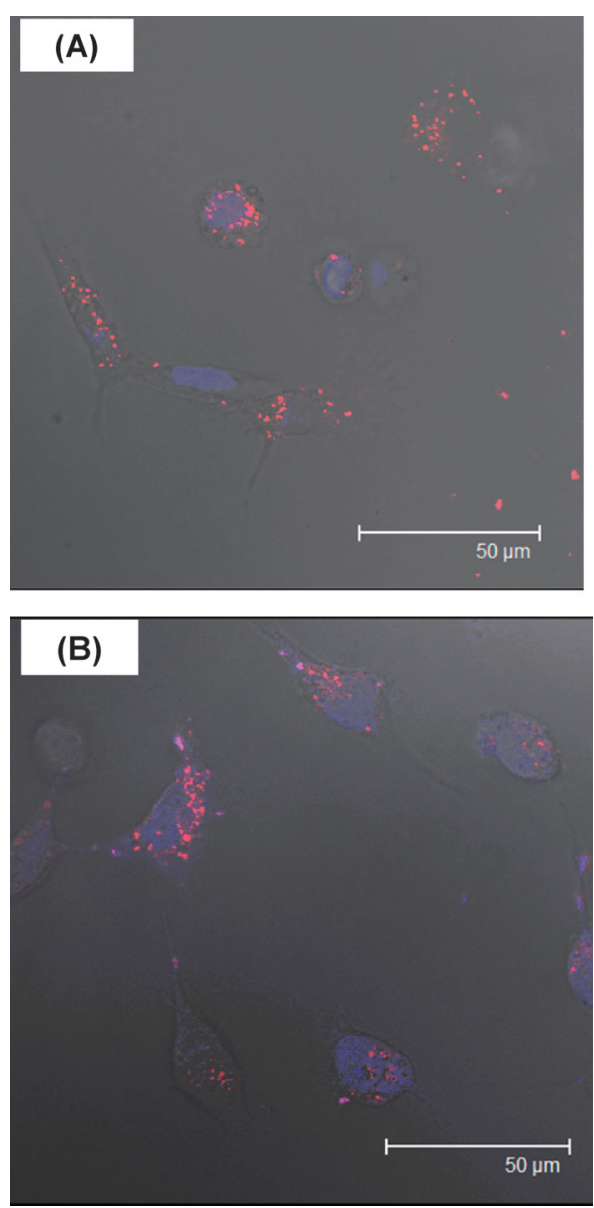

Fig. 3. Confocal Laser Images of Rhodamine-Labeled Plasmid (Red) in HeLa Cells Using the Cotransfection Method

HeLa cells were transfected with $2 \mu \mathrm{g}$ /dish of plasmid DNA without (A) and with $400 \mathrm{pmol}$ of mismatched siRNA in $3.5 \mathrm{~cm}$ glass-bottom dishes (B). Nuclei were stained with Hoechst 33258 (blue) 
pCMV-SPORT- $\beta$-gal plasmid (red). And the nuclei were stained with Hochst 33258 (blue). We observed the location of pDNA by confocal laser scanning microscopy. In both of

Table 1. The Anion Equivalent Ratio of siRNA for pDNA in the Cotransfection Experiment

\begin{tabular}{ccc}
\hline \hline $\begin{array}{c}\text { siRNA anionic molar conc. } \\
(\mathrm{pmol} / \mathrm{well})\end{array}$ & $\begin{array}{c}\mathrm{pDNA} \\
(\mu \mathrm{g} / \mathrm{well})\end{array}$ & $\begin{array}{c}\text { The anion equivalent ratio } \\
\text { of siRNA for pDNA }\end{array}$ \\
\hline 0 & 0.4 & 0 \\
5 & 0.4 & 0.22 \\
20 & 0.4 & 0.89 \\
80 & 0.4 & 3.57 \\
0 & 0.8 & 0 \\
5 & 0.8 & 0.11 \\
20 & 0.8 & 0.45 \\
80 & 0.8 & 1.79 \\
\hline
\end{tabular}

these dishes, pDNA was trasnsfected into the cells (Fig. 3). But, there was not a distinct difference of introduction of pDNA into cells between these dishes in this experiment.

[Exp. 3] Establishment of an Evaluation Method for siRNA Delivery by Using HeLa-luc Cells or CHO-luc Cells Carrying the Luciferase Reporter Gene We should use inducers to express luciferase in these HeLa-luc cells and CHO-luc cells. We considered that it is better to choose a shorter incubation time with inducers and lower inducer concentrations, because the inducers were shown to be cytotoxic for these mammalian cells. And, we considered that the number of seeded cells should be set to achieved was $90-95 \%$ confluent in luciferase assay. Thus, we optimized the inducing conditions for HeLa-luc cells and CHO-luc cells accordingly.

In the case of HeLa-luc cells, when the number of seeded cells was $6 \times 10^{3}$ cells/well, about $95 \%$ confluent was achiev-

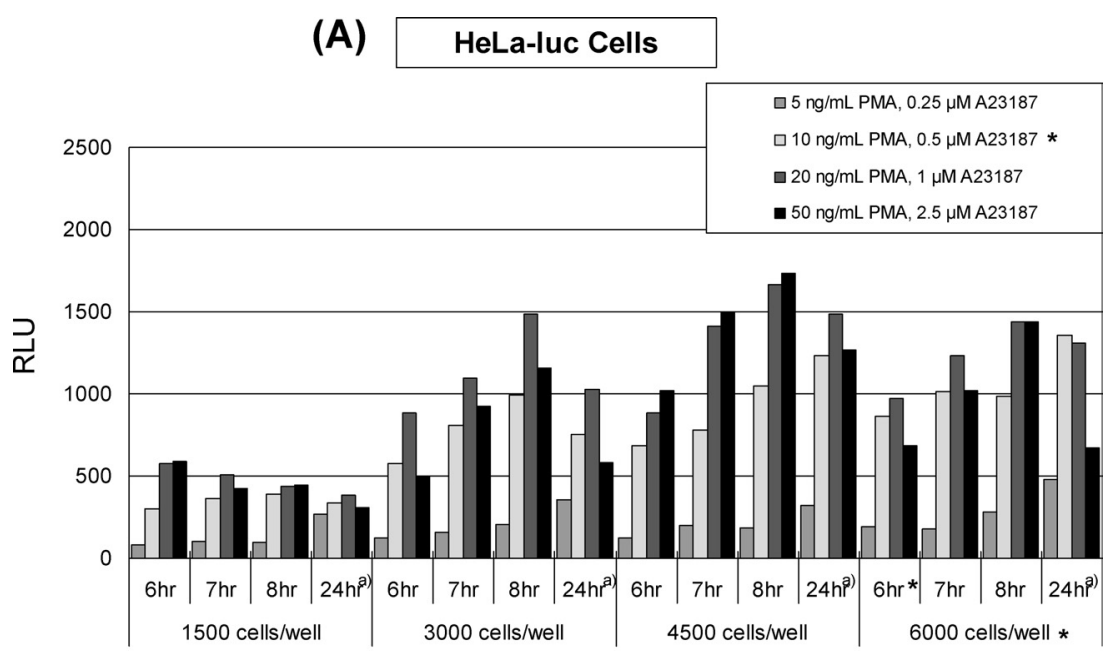

Incubation Time after Addition of Inducer

a): Change of cell shape

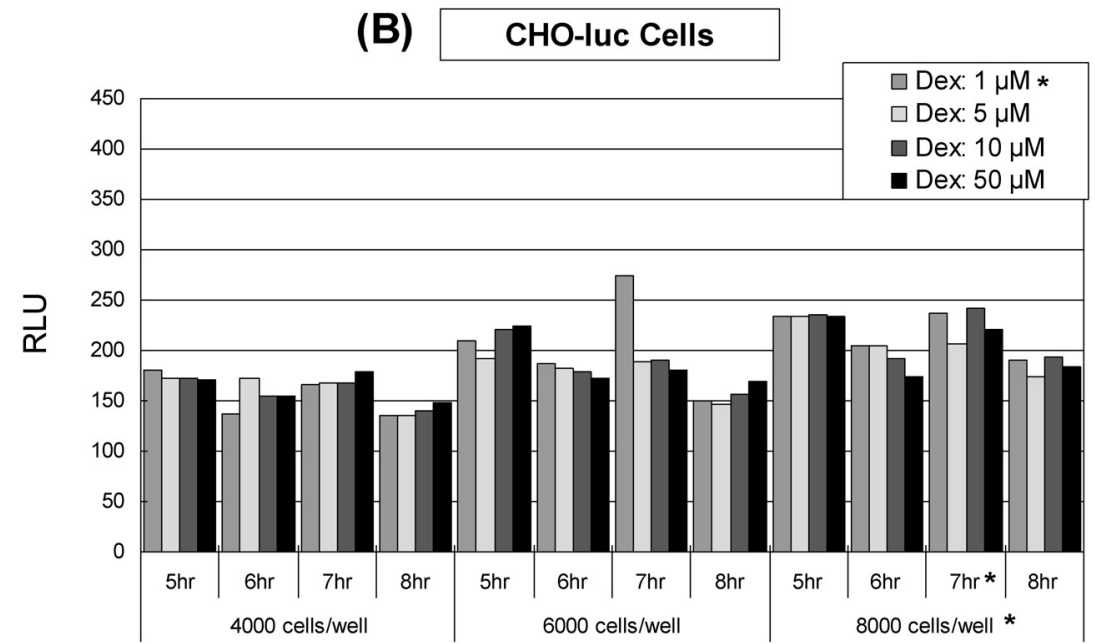

Incubation Time after Addition of Inducer

Fig. 4. Effect of Experimental Conditions on Luciferase Expression in HeLa-luc Cells (A) and CHO-luc Cells (B)

(A) HeLa-luc cells were seeded at 1.5, 3, 4.5, and $6 \times 10^{3}$ cells/well in 96-well plates. PMA and A23187 were added as inducers. The concentrations were 5, 10, 20, and 50 ng/ml of PMA, and $0.25,0.5,1$, and $2.5 \mu \mathrm{M}$ of A23187. The incubation times after addition of inducers were $6,7,8$, and $24 \mathrm{~h}$. The asterisk marks show the best respective conditions. (B) CHO-luc cells were seeded at 4,6 and $8 \times 10^{3}$ cells/well into 96 -well plates. Dexamethason (Dex) was added as inducer. The concentrations were $1,5,10$, and $50 \mu \mathrm{M}$ of Dex. The incubation times after addition of inducers were $5,6,7$, and $8 \mathrm{~h}$. The asterisk marks show the best respective conditions. 


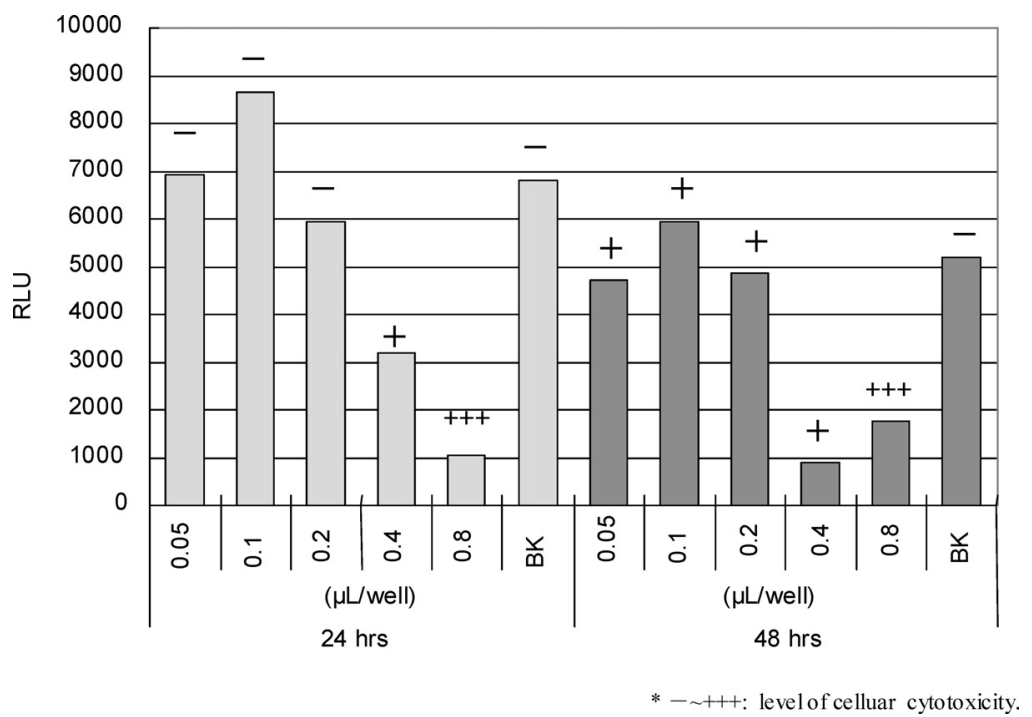

Fig. 5. Effects of Concentration and Transfection Time of Lipofectamine2000 in HeLa-luc Cells

HeLa-luc cells were seeded at $6 \times 10^{3}$ cells/well into 96 -well plates. Amounts of Lipofectamine2000 were $0.05,0.1,0,2,0.4$, and $0.8 \mu 1 /$ well. The transfection times were 24 or $48 \mathrm{~h}$. The levels of celluar cytotoxicities were shown above each bar.

ed in luciferase assay. For the inducer concentrations of $5 \mathrm{ng} / \mathrm{ml}$ of PMA and $0.25 \mu \mathrm{M}$ of A23187, luciferase was expressed at low level. However, when the inducer concentrations were $10 \mathrm{ng} / \mathrm{ml}$ of PMA and $0.5 \mu \mathrm{M}$ of A23187, luciferase was expressed at high level. Luciferase was expressed at high level in $6 \mathrm{~h}$ incubations with inducers, which was the shortest time condition of all (all of the conditions are indicated by the asterisk in Fig. 4A). In addition, when the HeLa-luc cells were incubated for $24 \mathrm{~h}$ with inducers, their shapes were changed.

In the case of CHO-luc cells, when the number of seeded cells was $8 \times 10^{3}$ cells/well, about $95 \%$ confluent was achieved in luciferase assay. For the inducer concentration of $1 \mu \mathrm{M}$ of Dex, which was the lowest concentration of all, luciferase was expressed at high level. The CHO-luc cells were less sensitive than HeLa-luc cells, so we considered that favorable incubation time was $7 \mathrm{~h}$, in which the highest luciferase activity in the condition of $8 \times 10^{3}$ cells/well for the number of seeded cells and $1 \mu \mathrm{M}$ of Dex (all of the conditions are indicated by the asterisk in Fig. 4B).

Furthermore, in the case of HeLa-luc cells, cellular cytotoxicity appeared after $24 \mathrm{~h}$ of incubation with more than $0.4 \mu \mathrm{l}$ of Lipofectamine2000/well. At incubations of $48 \mathrm{~h}$, however, cellular cytotoxicity appeared with more than $0.05 \mu \mathrm{l}$ Lipofectamine2000/well (Fig. 5). It was considered that total incubation time with Lipofectamine 2000 had to be $24 \mathrm{~h}$ for HeLa-luc cells. We outlined the optimised experimental conditions for siRNA transfection in HeLa-luc cells and CHO-luc cells in Chart 2.

[Exp. 4] Evaluation of the Activity of Commercially Available Reagents for siRNA Transfection (Chart 2) We evaluated the knockdown efficiency of six commercially available siRNA transfection reagents by using the procedure shown in Chart 2. The result is shown in Fig. 6. In addition, the volume of each reagent additive is given as "Amount ratio of reagent" (Table 2 ).

In the case of HeLa-luc cells, the highest effects were achieved with $1 / 2-1$ amount of Lipofectamine2000 (0.1$0.2 \mu \mathrm{l} /$ well $), 1$ amount of Genesilencer (1.0 $\mu \mathrm{l} /$ well), and 1
Table 2. Additive Volume of Six Commercially Available Transfection Reagents in Experiment 4

\begin{tabular}{|c|c|c|c|}
\hline Reagent name & $\begin{array}{c}\text { Package insert } \\
\text { instruction } \\
(\mu \mathrm{l} / \text { well })^{a)}\end{array}$ & $\begin{array}{l}\text { Additive } \\
\text { volume } \\
(\mu 1 / \text { well })^{a)}\end{array}$ & $\begin{array}{c}\text { Amount ratio } \\
\text { of reagent }\end{array}$ \\
\hline \multirow[t]{5}{*}{ Lipofectamine 2000} & 0.2 & 0.03 & $1 / 6$ \\
\hline & 0.2 & 0.05 & $1 / 4$ \\
\hline & 0.2 & 0.1 & $1 / 2$ \\
\hline & 0.2 & 0.2 & 1 \\
\hline & 0.2 & 0.4 & 2 \\
\hline \multirow[t]{5}{*}{ HiPerFect } & 0.8 & 0.13 & $1 / 6$ \\
\hline & 0.8 & 0.2 & $1 / 4$ \\
\hline & 0.8 & 0.4 & $1 / 2$ \\
\hline & 0.8 & 0.8 & 1 \\
\hline & 0.8 & 1.6 & 2 \\
\hline \multirow[t]{5}{*}{ GeneSilencer } & 1.0 & 0.17 & $1 / 6$ \\
\hline & 1.0 & 0.25 & $1 / 4$ \\
\hline & 1.0 & 0.5 & $1 / 2$ \\
\hline & 1.0 & 1.0 & 1 \\
\hline & 1.0 & 2.0 & 2 \\
\hline \multirow[t]{5}{*}{ Oligofectamine } & 0.6 & 0.1 & $1 / 6$ \\
\hline & 0.6 & 0.15 & $1 / 4$ \\
\hline & 0.6 & 0.3 & $1 / 2$ \\
\hline & 0.6 & 0.6 & 1 \\
\hline & 0.6 & 1.2 & 2 \\
\hline \multirow[t]{5}{*}{ TransIT-TKO } & 0.6 & 0.1 & $1 / 6$ \\
\hline & 0.6 & 0.15 & $1 / 4$ \\
\hline & 0.6 & 0.3 & $1 / 2$ \\
\hline & 0.6 & 0.6 & 1 \\
\hline & 0.6 & 1.2 & 2 \\
\hline \multirow[t]{5}{*}{ RNAiFect } & 1.6 & 0.27 & $1 / 6$ \\
\hline & 1.6 & 0.4 & $1 / 4$ \\
\hline & 1.6 & 0.8 & $1 / 2$ \\
\hline & 1.6 & 1.6 & 1 \\
\hline & 1.6 & 3.2 & 2 \\
\hline
\end{tabular}

a) 96-well plate

amount of TransIT-TKO $(0.6 \mu \mathrm{l} /$ well $)$; however, Lipofectamine2000 and TransIT-TKO caused cellular cytotoxicity under these conditions (Fig. 6A).

In the case of CHO-luc cells, the highest effects were achieved with $1-2$ amount of Lipofectamine2000 (0.2-0.4 


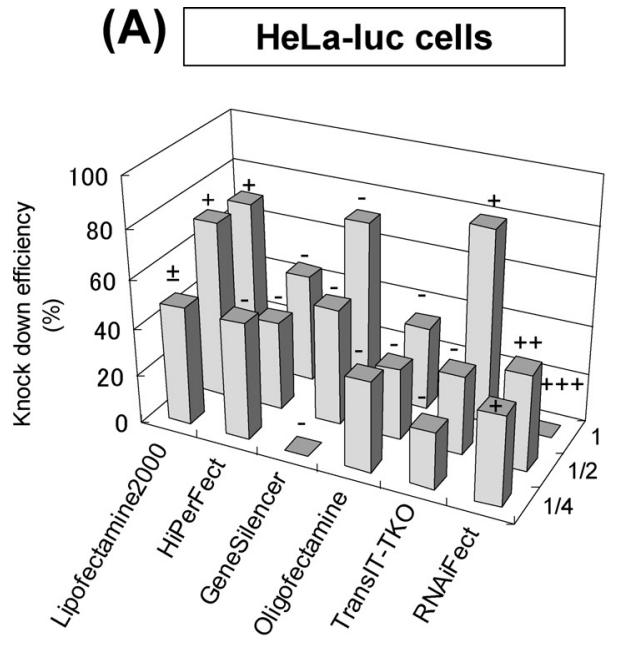

Reagent Name
(B) CHO-luc cells

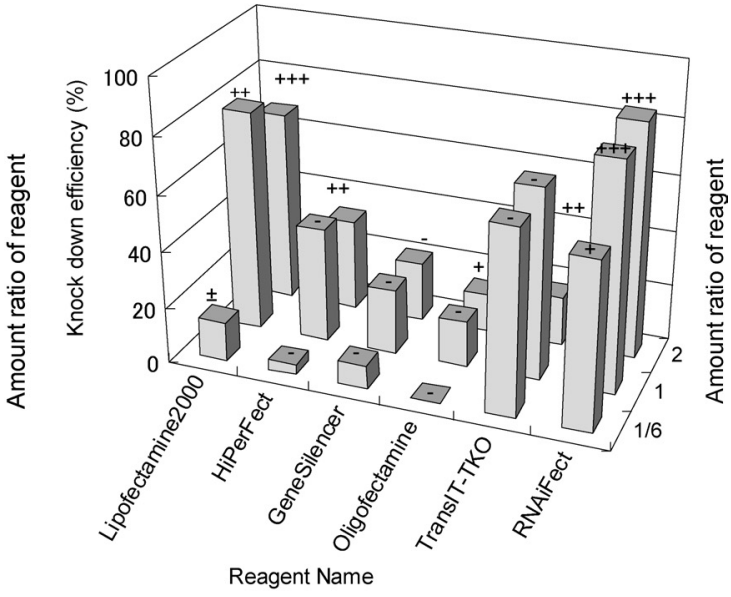

*- +++: level of celluar cytotoxicity.

Fig. 6. Knockdown Efficiency of Commercially Available Transfection Reagents in HeLa-luc Cells (A) and CHO-luc Cells (B)

(A) Six commercially available transfection reagents were added 1/4, 1/2 and 1 amount ratio of reagent, respectively. (B) Six commercially available transfection reagents were added 1/6, 1 and 2 amount ratio of reagent, respectively. The levels of celluar cytotoxicities were shown above each bar, respectively.

$\mu 1 /$ well $), 1 / 6-1$ amount of TransIT-TKO $(0.1-0.6 \mu 1 /$ well $)$, and $1-2$ amount of RNAFect (1.6-3.2 $\mu \mathrm{l} /$ well); however, Lipofectamine 2000 and RNAiFect caused severe cellular cytotoxicity at all conditions of addition (Fig. 6B).

There were no commercially available transfection reagents that decreased the luciferase activity by less than one tenth without causing cellular cytotoxicity.

\section{CONCLUSION}

In this report, we investigated the influence of siRNA on the transfection and expression of pDNA in the case of a cotransfection method in which both the plasmid and the siRNA were transfected simultaneously.

Even when mismatched siRNA was used, $\beta$-gal expression-positive cells were decreased and the degree of decrease depended on the amount of siRNA added. We cotransfectioned HeLa cells by using Rhodamine-labeled pCMVSPORT- $\beta$-gal plasmid and mismatched siRNA. But, there was not a distinct difference of introduction of pDNA into cells between using mismatched siRNA and without using it in this experiment.

However, we suggested that the cotransfection method should be avoided to evaluate the potency of siRNA or novel liposomal formulations for siRNA delivery.

Thus, if cells, such as HeLa-luc or CHO-luc, in which a target gene is stably inherited are commercially available, we should use them. Indeed, we established the evaluation method for siRNA delivery using these cells. As a consequence of checking the transfection efficiency of the commercialized transfection reagents for siRNA using this method, we found no commercially available transfection reagents which had a higher RNA interference effect without cytotoxicity.

Acknowledgements We are grateful to Dr. H. Harashima and Dr. H. Akita (Graduate School of Pharmaceutical Science, Hokkaido University) for labeling pDNA and for giving helpful advice.

\section{REFERENCES}

1) Fire A., Xu S., Montgomery M. K., Kostas S. A., Driver S. E., Mello C. C., Nature (London), 391, 806-811 (1998).

2) Kasim V., Taira K., Miyagishi M., J. Gene Med., 8, 782-791 (2006).

3) Ohki E. C., Tilkins M. L., Ciccarone V. C., Price P. J., J. Neurosci. Methods, 112, 95-99 (2001)

4) Rha S. J., Wang Y. P., J. Korean Med. Sci., 16, 567—572 (2001).

5) Kaul G., Amiji M., Pharm. Res., 22, 951-961 (2005).

6) Kikuchi A., Aoki Y., Sugiyama S., Serikawa T., Takakuwa K., Tanaka K., Suziki N., Kikuchi H., Hum. Gene Ther, 10, 947-955 (1999).

7) Akita H., Ito R., Khalil I. A., Futaki S., Harashima H., Mol. Ther., 9, $443-451$ (2004).

8) Tinsley R. B., Vesey M. J., Barati S., Rush R. A., Ferguson I. A., J. Gene Med., 6, 1023-1032 (2004). 